\title{
Food safety on board tankers. Results of analysis from “Healthy Ship” project
}

\author{
Stefania Scuri ${ }^{1}$, Fabio Petrelli ${ }^{1}$, Iolanda Grappasonni ${ }^{1}$, Marzio Di Canio ${ }^{2}$, \\ Andrea Saturnino $^{2}$, Fabio Sibilio ${ }^{2}$, Francesco Amenta ${ }^{1,2}$ \\ ${ }^{1}$ University of Camerino, School of Medicinal and Health Products Sciences, Camerino, Italy \\ ${ }^{2}$ Research Department, International Radiomedical Centre (CIRM), Rome, Italy
}

\begin{abstract}
Background: Microbiological monitoring of surfaces used for food preparation, as required by the Hazard Analysis and Critical Control Points (HACCP) plan, is important in risky conditions as those observed in the kitchens of ships. Limits to introduce a classification of risk levels and methods to adopt in conditions as those occurring in tankers have not been investigated. This paper presents the results of the "Healthy Ship" project on HACCP monitoring of surfaces used in food preparation on Italian flag tankers.

Materials and methods: Microbiological monitoring was carried out on 19 tankers between 2013 and 2017. Food handlers were also trained on board ship according to HACCP standards. Contact plates (ISO 18593:2004 compliant) were used to determine the colonies and bacterial charge according to the Wirtanen and Salo's method.

Results: A total of 1074 samples, 108 before the first course, 168 after the first course, 390 during the period of refresher (2015-2016), and 408 after the refresher training, were obtained from the three main kitchen surfaces: the worktop, cutting board, and kitchen sink. A good level of hygiene was observed in $56.9 \%$ of all samples, $0.1 \%$ were classified as adequate, and the remaining $43 \%$ as poor. The highest contamination was observed on the cutting board and kitchen sink and involved the total aerobic count. The only surface with inadequate levels of hygiene was the worktop. A reduction of contaminated samples was noted after training.

Conclusions: Our results suggest that continuous training should be provided for personnel responsible for handling foodstuffs on board ships.
\end{abstract}

(Int Marit Health 2019; 70, 1: 68-75)

Key words: microbiological surveillance, food-handling, seafarers, HACCP, food hygiene, food safety

\section{INTRODUCTION}

Food contamination can be attributed to natural contamination from raw materials (primary contamination) or to cross-contamination caused by the transfer of microorganisms from contaminated surfaces or vehicles (such as water, air, etc.) onto food. Appropriate standards of hygiene in the environment where food is prepared, such as surfaces, types of equipment and utensils are essential to prevent microbial contamination and to obtain safer food [1]. In the last decade, this topic has stimulated research to develop surfaces with antimicrobial activity [2-4].

This problem is more relevant in conditions characterised by a higher level of risk such as kitchens on board ships, and, in particular, the kitchens of cargo ships. Merchant (cargo) ships do not carry health professionals, may be involved in long journeys and seafarers work in an enclosed environment. Despite the low number of crew-members working and living on a cargo ship, seafarers are exposed to quite a high risk of infection [5-13]. To minimise the risk of infection and food poisoning in a closed environment such as the one found on a cargo-ship, ensuring microbiological safety in the kitchen should be a priority.

Taking into account that gastrointestinal disorders are at the first or second place as problems affecting seafarers healthy, the Centro Internazionale Radio Medico (CIRM) has 
launched a project called "Healthy Ship". This project includes a series of preventive measures aimed at protecting seafarers' health as a survey on the knowledge of seafarers about food hygiene, and a panel of interventions to improve the quality and the control of food and water distributed on board [13-18]. CIRM is the Italian Telemedical Maritime Assistance Service (TMAS) and represents the Centre with the largest worldwide experience [10, 12, 19]. This project included periodic training of galley's personnel and periodic on board inspections.

The present work reports the results of microbiological monitoring on the kitchen surfaces of cargo merchant ships before and after the seafarers training and suggests a new procedure for storing samples. Analysis started on August 2013 and was concluded in October 2017.

\section{MATERIALS AND METHODS}

\section{MICROBIOLOGICAL MONITORING}

Analysis of the microbiological safety of kitchens and of the compliance with good production practices was performed by a direct on board inspections done between August 2013 and October 2017, on tankers belonging to two shipping companies. Monitoring was carried out twice a year (frequency of 6/7 months) by medical and technical CIRM personnel on 19 ships, when they were docked. Ships were tankers shuttling service from not more than 6 years from the date of enrolment in the project. They were sailing from 7 to 10 days. Origin and destination were in the Mediterranean and in the Black sea. The "Healthy Ship" project established a training course on Hygiene and Sanitation for Ship's Messman and Stewards on the main rules of conduct and correct handling of foodstuffs foreseen by the Hazard Analysis and Critical Control Points (HACCP) plan on board ship as prevention of food-borne disease, HACCP and self-assessment, the HACCP principles and the keywords of the HACCP, food hygiene, personal hygiene, storage and labelling of leftovers. Courses were made by ship first officers, properly trained by the Hygiene group of the School of Pharmacy of Camerino University. Training lasted 1 week and was accompanied by a final exam, and the Italian Ministry of Health authorized the program. In 2013 , a preliminary monitoring was carried out to supervise of the hygienic level of the kitchen of cargo ships, and subsequently, the topics and the level of training were established (for the "Hygiene and Sanitation for Ship's Messman and Stewards" course). After the first training started in 2014, refresher training has been conducted between 2015 and 2016 only in the ships that have shown a negative trend of monitoring. The refresher training of personnel in each cargo ships has been conducted during different periods of this biennium, according to the availability of the ship in the port. Critical kitchen surfaces as sink, worktop and cutting boards were tested. These surfaces were chosen because the kitchens of ships are quite small and have few utensils or surfaces. It is impossible to identify different rooms to separate various levels of food processing as, for instance, the 'clean room' and the 'dirty room'. Food-handlers often manipulate food on the same surfaces, and for this reason we think it is necessary to monitor frequently used utensils or surfaces. The cutting board is a critical utensil because it is often used to cut clean and dirty foods as well as raw and cooked foods and is a critical point for cross-contamination. This study was carried out by monitoring kitchen surfaces with BIOLIFE contact plates with a diameter of $60 \mathrm{~mm}$ and a contact surface of $25 \mathrm{~cm}^{2}$ (ISO 18593:2004) [20]. The plates used included a Contact Plate Count Agar for identifying total aerobic bacteria (at $30^{\circ} \mathrm{C}$ ), a contact plate Violet Red Bile Agar to evaluate the number of coliforms (Escherichia coli) (at $37^{\circ} \mathrm{C}$ ) and a contact plate Sabouraud Dextrose Agar to count the total fungal load (at $25^{\circ} \mathrm{C}$ ) [21]. The sampling procedure applied was a development of the contact plate method. A contact plate filled with a suitable medium is pressed against the surface to be tested, avoiding lateral movements. The contact time was $10 \mathrm{~s}$ and a pressure obtained with a 500 g mass was applied onto surface. For each sampling point, a single contact plate agar surface specific for the test under examination, and a negative control was performed. Generally, the plates are incubated immediately after sampling. In order to analyse samples obtained on board ships, it is necessary to transport them from the ship to the laboratory. This may take days, depending on the ship's port of call. For this reason, the plates were stored at $4{ }^{\circ} \mathrm{C}$ and incubated after their arrival in the laboratory. To check if the above method was suitable, a validation procedure was performed.

\section{METHOD VALIDATION}

Before monitoring kitchen surfaces on board, the sampling procedure, using contact plates, was repeated 6 times, in duplicate, in the Hygiene Laboratory of Camerino University, to verify its implementation. For each replication a plate was incubated immediately after the sampling, other plates were incubated at $4^{\circ} \mathrm{C}$ after storage periods $(24,48,72$, $96 \mathrm{~h}$ ), and then incubated to count the number of Colony Forming Units on $20 \mathrm{~cm}^{2}$ (CFU/20 cm²). Total aerobic count, coliforms and fungal charge were tested independently. The data were transformed using Log10 and then over-dispersion and repeatability limits were calculated. Each test might be affected by casual errors caused by the way the samples were obtained, the temperature of incubation, the number of colonies, etc. The sum of these errors adds an additional dispersion of results, namely over-dispersion. This value is then added to the dispersion of the Poisson distribution. The 
Table 1. Limits for coliforms (E. coli), aerobic bacteria count and fungi, yeast and moulds proposed by Wirtanen and Salo [17]

\begin{tabular}{llll}
\hline Strict & $\begin{array}{l}\text { Coliforms } \\
\text { (Escherichia coli) } \\
\text { CFU/20 cm }\end{array}$ & $\begin{array}{l}\text { Aerobic bacteria count } \\
\text { CFU/20 } \mathbf{~ m}^{\mathbf{2}}\end{array}$ & $\begin{array}{l}\text { Fungi, moulds and yeast } \\
\text { CFU/20 } \mathbf{c m}^{\mathbf{2}}\end{array}$ \\
\hline Good quality & $<1$ & Up to 15 & Up to 1 \\
Adequate or not recommended & $<1$ & $15-50$ & $1-20$ \\
Poor & $\geq 1$ & $>50$ & $>20$
\end{tabular}

$\mathrm{CFU} / 20 \mathrm{~cm}^{2}$ - Colony Forming Units on $20 \mathrm{~cm}^{2}$

method could be considered valid if over-dispersion does not statistically modify the theoretical dispersion of Poisson data.

The statistical analysis was conducted using the formula:

$$
\chi_{n-1}^{2}=\frac{\sum_{i=1}^{n}\left(c_{i}-\bar{c}\right)^{2}}{\bar{c}}
$$

where $n$ is equal to number of observations, $c_{i}$ is the value given to each observation and $\bar{c}$ is the mathematical average of observations.

The data distribution was evaluated in agreement with the theoretical Poisson distribution if: $\left(\chi^{2}\right.$ experimental) $\leq \chi_{n-1}^{2}$ theoretical (with $n-1$ degrees of freedom, $p \geq 0.95$ ).

No significant differences were noticeable in the $\mathrm{CFU} / 20 \mathrm{~cm}^{2}$ results between plates incubated immediately after contact if stored at $4^{\circ} \mathrm{C}$. The method resulted was valid, and in particular: the test of aerobic bacteria count by a $\chi^{2}$ of $1.90 \leq \chi^{2}$ theoretical of $11.071(n=6 ; p \geq 0.95)$, the test for coliforms (Escherichia coli) by a $\chi^{2}$ of 2.144 $\leq \chi^{2}$ theoretical of $11.071(n=6 ; p \geq 0.95)$. The test for Enterococci by a $\chi^{2}$ of $1.903 \leq \chi^{2}$ theoretical of 11.071 $\left(n=6 ; p \geq 0.95\right.$ ) and the test for fungal by a $\chi^{2}$ of 3.687 $\leq \chi^{2}$ theoretical of $11.071(n=6 ; p \geq 0.95)$.

\section{HYGIENE CLASSIFICATION LEVEL}

Lacking an international classification, in this study, the hygiene level of the kitchen on board was categorized into classes of risk and consequently hygiene levels, applying the classification proposed by Wirtanen and Salo [17]. This method was based on three different scales and has three different levels of judgment for contact surfaces. The three scales in relation to the hazard level are loose, normal and strict. Levels are good (A), adequate (B) and poor (C). The limits for coliforms (Escherichia coli), aerobic bacteria count $\left(37^{\circ} \mathrm{C}\right)$ and fungi, yeast and moulds are summarised in Table 1.

\section{STATISTICAL ANALYSIS}

The results obtained for each parameter (Enterococci, Escherichia coli, total aerobic bacteria count at $37^{\circ} \mathrm{C}$, and total fungal charge) monitored were processed using a descriptive statistical analysis, the Shapiro-Wilk test for non-normality, and the Paired Student's t test using XLSTAT
Software [22]. In the Shapiro-Wilk test, if the data showed a $\mathrm{p}$-value $>\alpha$, the null hypothesis $(\mathrm{H} 0)$ could be accepted, and therefore the distribution resulted as normal [23].

To analyse the efficacy of training, the results obtained from the monitoring process conducted in the first visit and after the refresher training were compared using the Paired Student's t test. The variables on which the Paired Student's t test was based are shown by the number of colonies found, both before and after the safety inspection was conducted, relative to aerobic bacteria count, coliforms, Enterococci and fungal load, and the p-values at 95\% confidence interval were measured.

\section{RESULTS}

During the 4 years spent monitoring 19 ships, 1074 microbiological samples, 108 before the first course, 168 after the first course, 390 during the period of refresher (2015-2016), and 408 after the refresher training, from the three most critical surfaces (worktop, cutting board and kitchen sink) were collected and analysed.

When examining the percentage of positive samples over time, we noted a similar trend for all species monitored, and a decreasing of the positive samples percentage after the refresher training completed in 2016 (Fig. 1).

Among the total (1074) microbiological samples examined, a good level of hygiene was reported for the $56.9 \%$ of surfaces, $0.1 \%$ was classified as adequate and $43 \%$ as poor. In particular, after the first course, and before the refresher, the percentage of positive samples was $39.1 \%$; while after the refresher the number of positive samples was reduced to a percentage of $28.6 \%$.

This suggests that the development of the microbiological charge until 2016 is related with the lack of respect for good procedures by food handlers.

The results on surfaces classified as good, adequate and poor reported in percentage for each single surface are summarised in Figure 2.

Figure 2 shows that the "good level" is the level registered with the highest frequency for all microbiological parameter. An adequate level for aerobic bacteria counting was found only in a worktop sample, during the first inspection in 2013. In particular, the total aerobic count recorded 


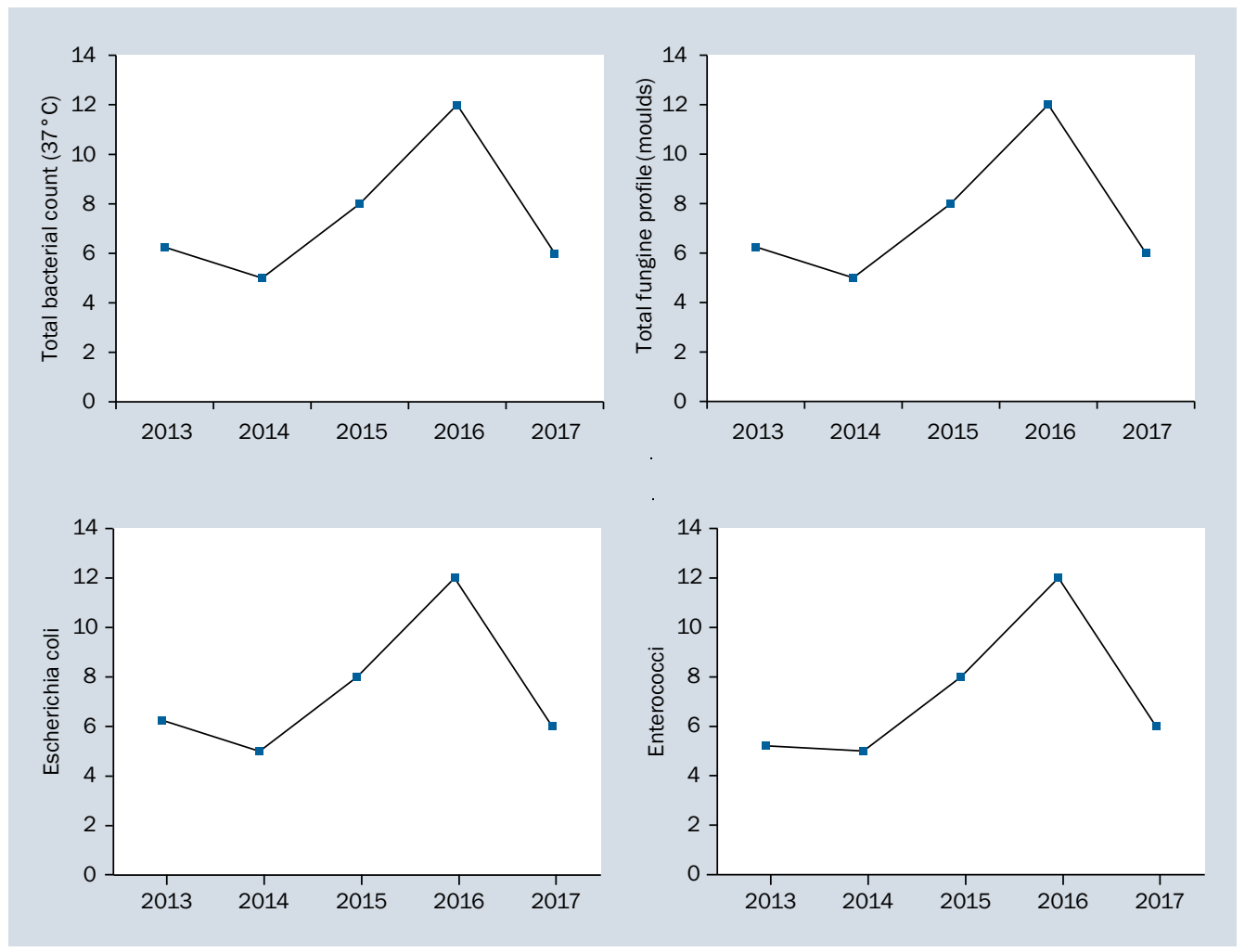

Figure 1. Percentage of positive samples in the years of monitoring

in this sample was $25 \mathrm{CFU} / 20 \mathrm{~cm}^{2}$, inside the range of 15 and $50 \mathrm{CFU} / 20 \mathrm{~cm}^{2}$, defined as an adequate level. Considering the surfaces classified as poor, the cutting board was recorded as the surface with the highest percentage of positive samples by fungal, Escherichia coli, and aerobic bacteria count. Whereas, the enterococci were recorded with the lowest percentage, but values were similar to the other microorganisms recorded.

In all tankers, a reduction in the frequency of positive samples was found. In fact, by evaluating the positivity or negativity of samples, a ratio of $0.5(50 \%)$ between poor and good samples in all ships was detected. Only one ship showed a ratio equal to $0.8(80 \%)$ among samples.

To test the effects of training, the average of the colony-forming units in the first sampling (year 2013) was compared with the average of colony-forming units detected in sampling after doing the refresher course (2017). As expected, the monitored surfaces in the first sample showed a CFUs concentration over the limits. In the second sample, the concentration of CFUs was within limits, with a higher than $99 \%$ reduction for all surfaces. Different levels of contamination were found among surfaces. The kitchen sink and the cutting-board had the highest contamination levels of total bacteria count at $37^{\circ} \mathrm{C}$. The worktop was contaminated too, but showed a lower concentration of mi- croorganisms. When considering the microorganisms found in a higher frequency, the total bacterial count at $37^{\circ} \mathrm{C}$ on all surfaces was the principal cause of microbial contamination (Fig. 3). The total fungal charge showed a similar trend on all surfaces while the Enterococci were found in a higher concentration on the worktop. The highest concentration of Escherichia coli was detected on the worktop and on the cutting board (Fig. 3).

Sanitary conditions were positive after seafarers employed in the kitchen underwent a period of training. In fact, after the first surveillance (2013) followed by a negative outcome, a food safety training was conducted and during the second inspection the efficacy of this training was evaluated. After the training was carried out, all surfaces showed a decrease in the level of microbial charge. This result was common for all microorganisms and for all surfaces (Fig. 3). Analysing the percentage of reduction of CFUs between the first surveillance and the surveillance after refresher, the highest percentage of reduction (100\%) was noticeable for Escherichia coli and Enterococci in all surfaces monitored, whereas a reduction of $97.9 \%$ of the total aerobic charge was obtained for the worktop. The distribution resulted as normal and the Student's t-test showed the efficacy of the food safety training especially in the reduction of total bacteria count, the principle cause of contamination (Table 2). 


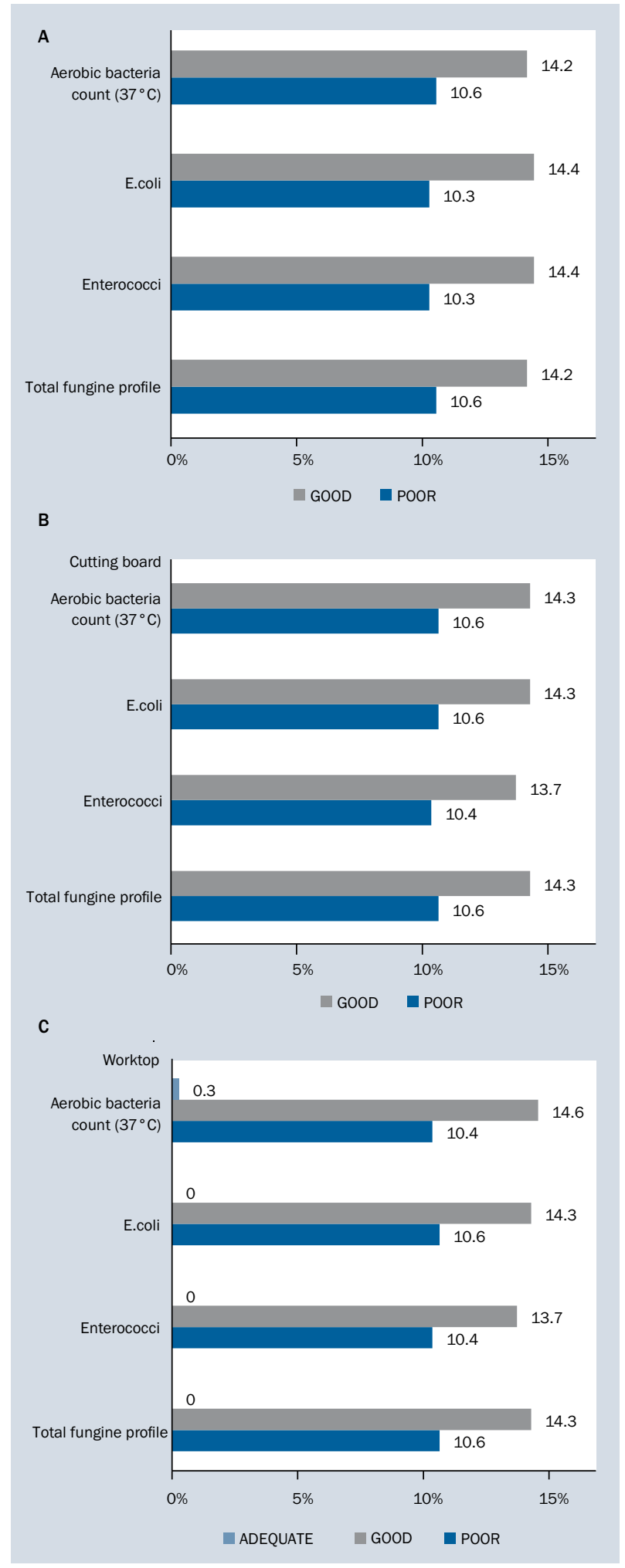

Figure 2. Percentage of surfaces classified as poor, adequate, and good (on 1074 samples): kitchen sink sampled: $n=360$ (A); cutting board sampled: $n=357$ (B); work top sampled: $n=357$ (C)

\section{DISCUSSION}

This paper has looked at the procedures applied to identify the level of microbial contamination over all surfaces in contact with food and, in particular, the efficacy of training given to food handlers on board tankers.

In our work, surfaces used in food production on board cargo ships were categorised as strict and not normal or loose, because they are exposed to a high risk of contamination due to the hard conditions on cargo ships [17, 24-30]. In these surfaces, a microbiological survey was conducted to identify the ones which were more susceptible to the risk of contamination. Even if the number of samples increased over time, the decrease in the percentage of contaminated samples showed that the training program on safe food handling on good handling practices (GHP) (surfaces sanitation procedures), followed by continuous inspections on board, ensured surfaces were under control.

In terms of evaluation of the effects of monitoring surfaces initially classed under a "poor" level of hygiene reached an "adequate" level after the second visit. Analysis of the statistical significance value of the Student's t test obtained in correlating the microbiological charge, in particular of total bacterial count $\left(37^{\circ} \mathrm{C}\right)$, between the first and second visit showed the positive effect on the hygienic quality of surfaces monitored and allowed the real value of intervention to be evaluated. This result is comparable with similar findings of other researchers that emphasized the importance of training food services staff on board ships [25].

Microbiological surveillance revealed a relevant percentage (43\%) of surfaces classified as "poor".

Probably, the bacteria come from the manipulation of foods by food-handlers. In fact, after checking the compliance of the storage temperature of food boarded, and of the cooling room temperature, we have investigated the compliance of sanitisation procedures. As a result, we have found a cleaned cold room, while all the criticalities were observed in the kitchen where the ordinary manipulations of food take place. In particular, the greater contamination was related to total mesophilic aerobic counts. This charge is a standard parameter used to assess the microbiological quality of surfaces used by food-handlers. In particular, an increase of the total mesophilic charge could be caused by the presence of microorganisms transferred by food employees, particularly by using dirty hands.

The presence, on surfaces monitored, of some bacteria such as Enterococci and Gram-negative, such as coliforms (Escherichia coli), suggests strengthening the knowledge and procedures relating to the personal hygiene of food-han- 
A

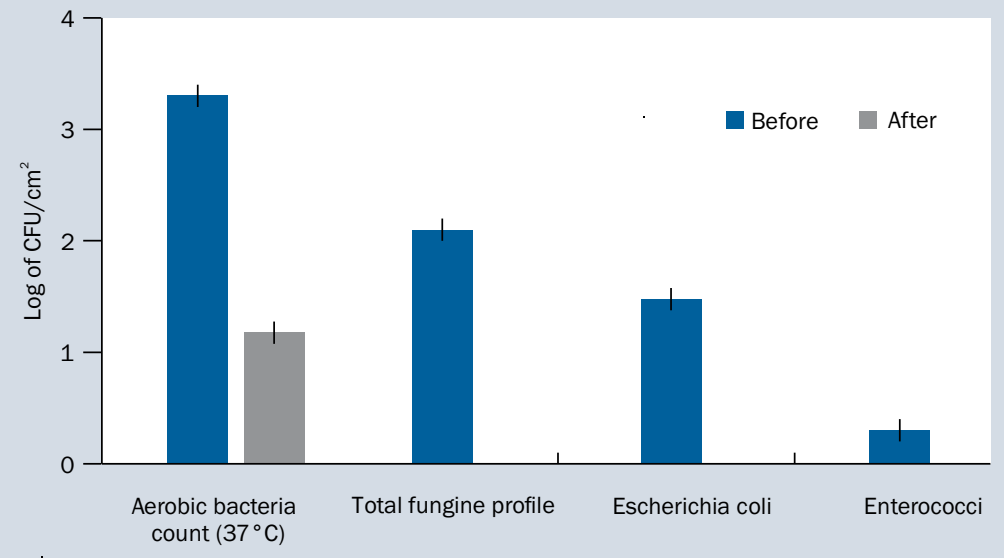

B

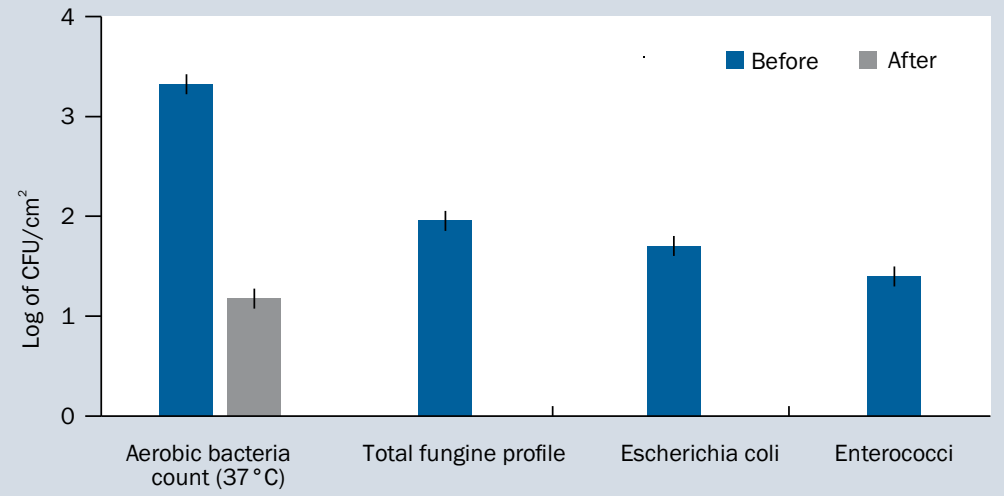

C

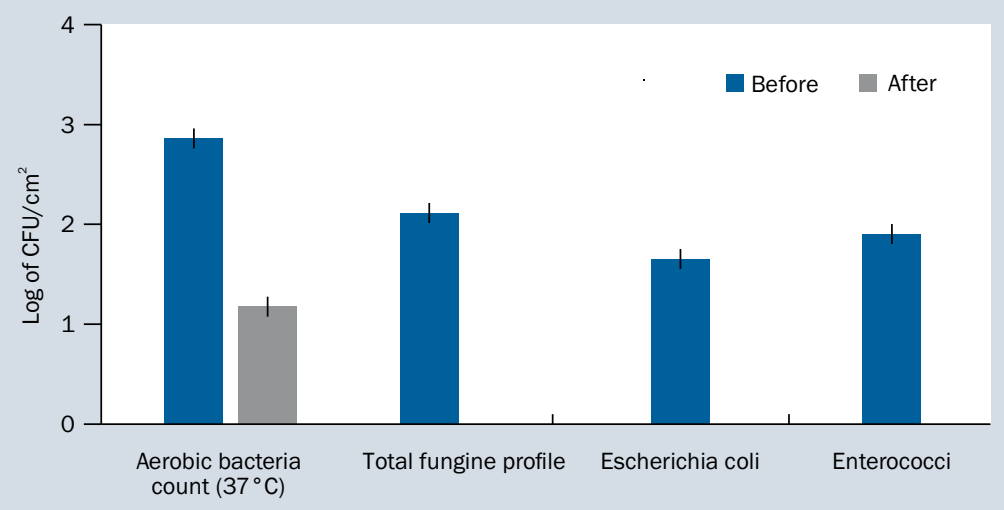

Figure 3. Microbiological charge detected in the first sampling before the first training course, year 2013 (before) and after doing a new refresher course, year 2017 (after); A. Kitchen sink sampled: $n=172$ (36 before and 136 after); B. Cutting board sampled: $n=172$ (36 before and 136 after); C. Work top sampled: $n=172$ (36 before and 136 after); CFU - Colony Forming Units

dlers and their environment [31-33]. Coliforms (Escherichia coli), associated with a high aerobic mesophilic bacteria count, revealed a lack in the sanitation procedures because aerobic heterotrophic bacteria are more capable of growing on surfaces enriched by food residuals. For instance, the high contamination recorded on the cutting board with the lack of respect for the GHPs can be explained. The presence of Enterococci, even if detected with a lower number of viable counts than Escherichia coli, has been a severe hazard of contamination for the seafarer's health. In fact, Enterococci are common in the environment, and when present in food they can infect people, causing severe infections [34]. 
Table 2. Paired Student's t-test

\begin{tabular}{lll}
\hline Sample & P-value: before-refr vs. after-refr & 95\% confidence interval \\
\hline Total bacterial count $\left(37^{\circ} \mathrm{C}\right)$ & $0.00^{*}$ & 1054.58 to 1613.42 \\
Total fungine profile & 0.08 & -15.78 to 102.45 \\
Escherichia coli & 0.05 & 0.41 to 62.92 \\
Enterococci & 0.27 & -43.89 to 90.56 \\
${ }^{*} p<0.05 ;$ before-refr - first sampling, before the first training; after-refr - after doing a new refresher course &
\end{tabular}

The sampling of fungi showed they were present in all surfaces monitored. This result suggests the environmental conditions of the kitchen should be further investigated, particularly levels of aeration and damp.

The training of seafarers on HACCP and the constant monitoring practices on board promoted a decrease of microbial positive samples. The ratio of 0.5 (50\%) between positive and negative samples collected on cargo ships showed that microbiological surveillance achieved only half the objective. In this respect, we should mention that during the inspections, some unsafe practices such as the production of food in high quantities with consequent storage of leftovers were recorded. In fact, the production of surplus food was closely related to the risk of undercooked food and cross-contamination. Recent studies have shown that even at low temperatures, some bacteria such as Salmonella spp., are able to contaminate meat (poultry), highlighting the risks of consuming undercooked meat $[35,36]$.

A correct implementation of GHPs within a HACCP plan is the principal practical measure used to stop the spread of cross-contamination. In fact, cross-contamination events were attributed to deficient hygiene practices, contaminated equipment, contamination via food handlers, processing, or inadequate storage, generally a result of poor hygiene [37, 38]. The results of this study suggest checks on board merchant ships should be continued to improve sanitation standards operating procedures (SSOPs) and, finally, to enforce the knowledge of food handlers employed on board. In comparison to other studies [23, 39] that evaluated positive effects after training, in our case constant monitoring allowed critical hygienic conditions to be found.

\section{CONCLUSIONS}

Our study suggests that it is necessary to carry out a constant activity of training on food handlers over time to take under control the contamination episodes. The fact that merely introducing a HACCP plan is not sufficient to remove the mishandling of food, but continuous monitoring on board combined with refresher training for the seafarers must be adopted, is an important result of our study, as well as one of its strong points. In fact, only by applying this type of approach it will be possible to keep the hygiene level of kitchens on board ship under control. Furthermore, this research demonstrated the possibility of carrying out microbiological monitoring on board cargo ships docked far away, proposing restrictive limits to classify the hygiene levels of surfaces used for food preparation. However, one limit of this study was given by the restricted number of ships used in the study as well as the difficulty of carrying out continuous monitoring, as is normally done on land, on ships which are often at sea for long periods of time.

It is important to remember that seafarers represent one of the most isolated demographic working groups in the world, with limited access to medical care because they are at sea for days or weeks before ships can reach a port and also are exposed to high physical stress [40-42].

\section{REFERENCES}

1. Osimani A, Garofalo C, Clementi F, et al. Bioluminescence ATP monitoring for the routine assessment of food contact surface cleanliness in a university canteen. Int J Environ Res Public Health. 2014; 11(10): 10824-10837, doi: 10.3390/ijerph111010824, indexed in Pubmed: 25329534.

2. Cabezas-Pizarro J, Redondo-Solano M, Umaña-Gamboa C, et al. Antimicrobial activity of different sodium and potassium salts of carboxylic acid against some common foodborne pathogens and spoilage-associated bacteria. Rev Argent Microbiol. 2018; 50(1): 56-61, doi:10.1016/j.ram.2016.11.011, indexed in Pubmed: 28947089.

3. Marchetti F, Palmucci J, Pettinari C, et al. Preparation of Polyethylene Composites Containing Silver(I) Acylpyrazolonato Additives and SAR Investigation of their Antibacterial Activity. ACS Appl Mater Interfaces. 2016; 8(43): 29676-29687, doi: 10.1021/acsami.6b09742, indexed in Pubmed:27762551.

4. Marchetti F, Palmucci J, Pettinari C, et al. Linkage Isomerism in Silver Acylpyrazolonato Complexes and Correlation with Their Antibacterial Activity. Inorg Chem. 2016; 55(11): 5453-5466, doi: 10.1021/acs. inorgchem.6b00495, indexed in Pubmed: 27177324.

5. World Health Organization (WHO). WHO Estimates of the Global Burden of Foodborne diseases. 2015. Available on:.http://www. who.int/foodsafety/areas_work/foodborne-diseases/ferg/en/ (Last accessed: 2018, June 14).

6. Grappasonni I, Petrelli F, Amenta F. Deaths on board ships assisted by the Centro Internazionale Radio Medico in the last 25 years. Travel Med Infect Dis. 2012; 10(4): 186-191, doi: 10.1016/j. tmaid.2012.06.006, indexed in Pubmed: 22819258.

7. Siracusa M, Petrelli F. [Trade of food supplement: food or drug supplement?]. Recenti Prog Med. 2016; 107(9): 465-471, doi: 10.1701/2354.25224, indexed in Pubmed: 27727254. 
8. Cuccioloni M, Bonfili L, Mozzicafreddo M, et al. Mangiferin blocks proliferation and induces apoptosis of breast cancer cells via suppression of the mevalonate pathway and by proteasome inhibition. Food Funct. 2016; 7(10): 4299-4309, doi: 10.1039/c6fo01037g, indexed in Pubmed: 27722367.

9. Pavli A, Maltezou HC, Papadakis A, et al. Respiratory infections and gastrointestinal illness on a cruise ship: A three-year prospective study. Travel Med Infect Dis. 2016; 14(4): 389-397, doi: 10.1016/j. tmaid.2016.05.019, indexed in Pubmed: 27320130.

10. Grappasonni I, Paci P, Mazzucchi F, et al. Awareness of health risks at the workplace and of risks of contracting communicable diseases including those related to food hygiene, among seafarers. Int Marit Health. 2012; 63(1): 24-31, indexed in Pubmed: 22669809.

11. Grappasonni I, Marconi D, Mazzucchi F, et al. Survey on food hygiene knowledge on board ships. Int Marit Health. 2013; 64(3): 160-167, indexed in Pubmed: 24072544.

12. Grappasonni I, Petrelli F, Scuri S, et al. Knowledge and Attitudes on Food Hygiene among Food Services Staff on Board Ships. Ann Ig. 2018; 30(2): 162-172.

13. Grappasonni I, Cocchioni M, Degli Angioli R, et al. Recommendations for assessing water quality and safety on board merchant ships. Int Marit Health. 2013; 64(3): 154-159, indexed in Pubmed: 24072543.

14. Siracusa M, Grappasonni I, Petrelli F. The pharmaceutical care and the rejected constitutional reform: what might have been and what is. Acta Biomed. 2017; 88(3): 352-359, doi: 10.23750/abm. v88i3.6376, indexed in Pubmed: 29083342.

15. Signorelli C, Odone A, Gozzini A, et al. The missed Constitutional Reform and its possible impact on the sustainability of the Italian National Health Service. Acta Biomed. 2017; 88(1): 91-94, doi: 10.23750/abm.v88i1.6408, indexed in Pubmed: 28467341.

16. Food and Agriculture Organization of the United Nations World Health Organization (FAO-WHO). Exposure assessment of microbiological hazards in food. Guidelines, 2008 (Microbiological Risk Assessment Series; 7). Available on:. http://www.fao.org/docrep/010/a0251e/ a0251e00.htm (Last accessed: 2018, June 14)

17. Wirtanen G, Salo S. Microbial limits used for various types of food process surfaces based on case study evaluations. J Hygienic Engin Design. 2012; 1: 57-61.

18. International Labour Office (ILO). Guidelines on the training of ships' cooks. 2014: Geneva.

19. Mahdi SS, Amenta F. Eighty years of CIRM. A journey of commitment and dedication in providing maritime medical assistance. Int Marit Health. 2016; 67(4): 187-195, doi: 10.5603/IMH.2016.0036, indexed in Pubmed: 28009394.

20. International Standards Microbiology of food and animal feeding stuffs Horizontal methods for sampling techniques from surfaces using contact plates and swabs (ISO 1. 8593; 2004.

21. Technical schedule of Biolife italiana s.r.l. $n^{\circ}$ 498010V B1-4.; 04: 2004.

22. Addinsoft SA. XLstat 2006. Loading Data Analysis and Statistical Solution for Microsoft Excel. Addinsoft SRL. 2006.

23. Capunzo M, Cavallo P, Boccia G, et al. Food hygiene on merchant ships: the importance of food handlers' training. Food Control. 2005; 16(2): 183-188, doi: 10.1016/j.foodcont.2004.01.010.

24. Cushnie T, Lamb A. Antimicrobial activity of flavonoids. Int J Antimicrobial Agents. 2005; 26(5): 343-356, doi: 10.1016/j.ijantimicag.2005.09.002.

25. Soon JM, Baines R, Seaman P. Meta-analysis of food safety training on hand hygiene knowledge and attitudes among food handlers. J Food Prot. 2012; 75(4): 793-804, doi: 10.4315/0362-028X. JFP-11-502, indexed in Pubmed: 22488073.

26. ILSI Europe Risk Analysis in Microbiology Task Force. Available on:. http://ilsi.eu/task-forces/food-safety/microbiological-food-safety (Last accessed: 2018, June 14)
27. Satin M. Food alert!: the ultimate sourcebook for food safety. 2th ed. New York: Facts On File, Inc. Infobase Publishing. 2008.

28. Ilkan Ali Olgunoglu. Determination of Microbiological Contamination Sources of Blue Crabmeat (Callinectes sapidus Rathbun, 1896) During Pasteurization Process. Pakistan J Zool. 2010; 42(5): 545-550.

29. Khangholi M, Jamalli A. The effects of sugars on the biofilm formation of on stainless steel and polyethylene terephthalate surfaces in a laboratory model. Jundishapur J Microbiol. 2016; 9(9): e40137, doi: 10.5812/jjm.40137, indexed in Pubmed: 27800149.

30. Beloin C, Roux A, Ghigo JM. Escherichia coli biofilms. Curr Top Microbiol Immunol. 2008; 322: 249-289, indexed in Pubmed: 18453280.

31. Soares-Santos V, Barreto AS, Semedo-Lemsaddek T. Characterization of Enterococci from Food and Food-Related Settings. J Food Prot. 2015; 78(7): 1320-1326, doi: 10.4315/0362-028X.JFP-14-419, indexed in Pubmed: 26197283.

32. Adams RI, Miletto M, Taylor JW, et al. The diversity and distribution of fungi on residential surfaces. PLoS One. 2013; 8(11): e78866, doi:10.1371/journal.pone.0078866, indexed in Pubmed: 24223861.

33. Tozzo K, Neto AFG, Spercoski KM, et al. Migration of Salmonella serotypes Heidelberg and Enteritidis in previously frozen chicken breast meat. Food Microbiol. 2018; 69: 204-211, doi: 10.1016/j. fm.2017.07.021, indexed in Pubmed: 28941903.

34. United States Department of Agriculture (USDA). Food Safety and Inspection Service (FSIS). Leftovers and Food Safety. 2013. Available on: tovers-and-food-safety [Last accessed: 2018, June. https:// www.fsis.usda.gov/wps/portal/fsis/topics/food-safety-education/ get-answers/food-safety-fact-sheets/safe-food-handling/leftovers -and-food-safety (Last accessed: 2018, June 14).

35. Pérez-Rodríguez F, Valero A, Carrasco E, et al. Understanding and modelling bacterial transfer to foods: a review. Trends in Food Science \& Technology. 2008; 19(3): 131-144, doi: 10.1016/j. tifs.2007.08.003.

36. Pérez-Rodríguez F, Valero A, Todd ECD, et al. Modeling transfer of Escherichia coli 0157:H7 and Staphylococcus aureus during slicing of a cooked meat product. Meat Sci. 2007; 76(4): 692-699, doi: 10.1016/j. meatsci.2007.02.011, indexed in Pubmed: 22061246.

37. Ravishankar S, Zhu L, Jaroni D. Assessing the cross contamination and transfer rates of Salmonella enterica from chicken to lettuce under different food-handling scenarios. Food Microbiol. 2010; 27(6): 791-794, doi: 10.1016/j.fm.2010.04.011, indexed in Pubmed: 20630321.

38. World Health Organization (WHO). Foodborne disease outbreaks: Guidelines for Investigation and Control. France. 2008. Available on: .http://apps.who.int/iris/bitstream/handle/10665/43771/9789241547222_eng.pdf?sequence=1 (Last accessed: 2018, June 14)

39. Brunetti L, De Caro F, Boccia G, et al. Surveillance of nosocomial infections: a preliminary study on yeast carriage on hands of healthcare workers. J Prev Med Hyg. 2008; 49(2): 63-68, indexed in Pubmed: 18847179.

40. Martarelli D, Cocchioni M, Scuri S, et al. Cold exposure increases exercise-induced oxidative stress. J Sports Med Phys Fitness. 2011; 51(2): 299-304, indexed in Pubmed: 21681166.

41. Martarelli D, Cocchioni M, Scuri S, et al. Diaphragmatic breathing reduces postprandial oxidative stress. J Altern Complement Med. 2011; 17(7): 623-628, doi: 10.1089/acm.2010.0666, indexed in Pubmed: 21688985.

42. Peretti A, Amenta F, Tayebati SK, et al. Telerehabilitation: review of the state-of-the-art and areas of application. JMIR Rehabil Assist Technol. 2017; 4(2): e7, doi: 10.2196/rehab.7511, indexed in Pubmed: 28733271. 